\title{
Modeling of BSA-Metal Ion-Acrylic Acid Complex by Theoretical Methods: Semi-Empirical PM6 and Docking Study
}

\author{
V. EnisoĞLu AtalaY*, İ. Bariş ÖlüÇ And M. Karahan \\ Üsküdar University, Department of Bioengineering, Istanbul, Turkey
}

(Received June 21, 2018; in final form October 12, 2018)

\begin{abstract}
Albumin is the most prominent plasma protein, and one of its main functions is the transport of a large number of chemical compounds. In order to understand the nature of the transport and distribution of these compounds within biological organisms, it is important to examine the interactions of ions and molecules with proteins. In this work, the binding constants of experimentally studied metal-BSA complexes were calculated by using computational chemistry and molecular docking methods. Bovine serum albumin (BSA), polyacrylic acid $(\mathrm{PAA})$ and eight different metal ions $\left(\mathrm{Cd}^{2+}, \mathrm{Co}^{2+}, \mathrm{Cu}^{+}, \mathrm{Cu}^{2+}, \mathrm{Fe}^{2+}, \mathrm{Mn}^{2+}, \mathrm{Ni}^{2+}\right.$ and $\left.\mathrm{Zn}^{2+}\right)$ were investigated by molecular docking study. The study was carried out in two stages. As the first step, the stability of the complexes was calculated by PM6 method. In the second step, the complex formation energies of the stable ligands were performed using AutoDock 4.2. BSA- $\mathrm{Cu}^{2+}$-PAA complex was found to be the most stable complex in all the metal complexes that have been studied so far whereas BSA-PAA complex structure was not subjected to experimental study with $\mathrm{Cu}^{+}$ion previously. In this study, BSA-Cu ${ }^{+}-\mathrm{PAA}$ complex was found to be the most stable (binding energy: $-8.15 \mathrm{kcal} / \mathrm{mol}$ ) which gave the best binding energy in the obtained results.
\end{abstract}

DOI: 10.12693/APhysPolA.134.1200

PACS/topics: BSA, docking study, PM6, binding energy, metal complex

\section{Introduction}

The most well-known function of albumin is protein structures which allow the transport of a large number of chemical compounds. Many endogenous and exogenous compounds are transported after entering the bloodstream (including drugs, hormones, xenobiotics and fatty acids) as a complex with serum albumin [1]. This kind of protein also contributes to the maintenance of colloid blood osmotic pressure and blood $\mathrm{pH}[2,3]$, but one of the most important properties of albumin is that it can be reversibly attached to different compounds. In order to understand the nature of the transport and distribution of these species in biological systems, it is important to examine the interactions of ions and molecules with proteins [4-6]. Coordination compounds offer interesting opportunities with a wide variety of geometries and coordination numbers, which can be demonstrated with adjustable ligand kinetic, redox activity and metal ions, as well as pharmacologically unique high structural diverse properties in the design of new active molecules [7]. On the other hand, it has been suggested that the smoothness of the ligands coordinating the metal center in metal complexes plays an important role in medicinal drugs [8].

Drug-serum albumin (SA) interactions play an important role in pharmacokinetics and pharmacodynamics. The settlement, distribution, half-life, and metabolism of many biologically active compounds in the body have

\footnotetext{
* corresponding author; e-mail: vildan.enisoglu@uskudar.edu.tr
}

been linked to their binding propensity to SA [9-11]. The BSA protein comes from two chain (A and B) including 583 amino acids. Structurally, BSA has three homologous regions (I-II-III): I (residues I-195), II (196-383), and III (384-583) [12] and has two TRP centers (TRP134 and TRP213). BSA TRP213 is similar to central human serum albumin (HSA) TRP214 center [13]. Like other serum albumin, BSA also possesses a wide range of physiological functions related to the binding, transit and distribution of biologically active compounds [1416]. In recent years, BSA complexes have been used as therapeutic agents against bacterial, viral, fungal infections, and different types of tumors [17, 18], as well as radiopharmaceuticals, superoxide dismutase, and insulin mimics [19] including bioinorganic chemistry. BSA binds to a variety of soluble and insoluble drugs and strongly influences the way they are transported in the body. Numerous single-nucleated and multicore $\mathrm{Cu}^{2+}, \mathrm{Ni}^{2+}$, $\mathrm{Zn}^{2+}, \mathrm{Co}^{2+}, \mathrm{Pt}^{2+}$ complexes have been investigated for BSA interaction and its binding ability with aromatic ligands (some of which carry known pharmacologically active moieties) [2, 3, 8, 20-22].

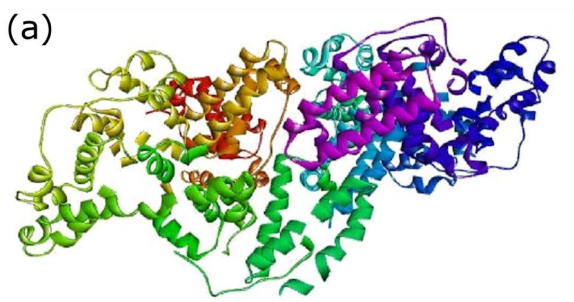

(b)

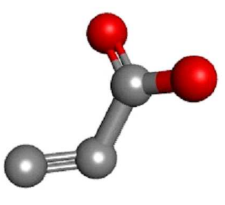

Fig. 1. (a) BSA (pdb code:4OA0), (b) acrylic acid (Discovery Studio 4.1 Visualizer. 
Presently, the formation of triple polycomplexes of synthetic polyelectrolytes and watersoluble and waterinsoluble biomolecules in the presence of transition metal ions is designed by using in vivo methods. In this study, BSA (pdb code:4OA0) and PAA (Fig. 1a-b) complex formation process was investigated in the presence of the particular metal ions. The stability and binding constants of transition metal-BSA complexes were calculated by using computational chemistry methods in our experimental study.

\section{Methods}

\subsection{Geometry optimizations}

In this study, the stable conformation of acrylic acid (AA) was first found using Spartan 04 [23] program. To understand which BSA-PAA-ion complex is more stable, firstly the PAA-ion coordination number was determined. Geometry optimizations were made to investigate monomer, dimer, trimer, and tetramer configurations of PAA with the metal ion. According to the lowest energy principle, which PAA-ion complex was more stable was decided. Linear, trigonal planar, tetrahedral and bipyramidal complex structures for trimer form and trigonal, bipyramidal, tetrahedral, octahedral, squareplaner and seesaw structures for tetramer form were drawn using GaussView5.0 [24] for computational analysis purposes and $\mathrm{Cu}^{+}$ion was selected as metal ion. All computations were performed with semi-empirical PM6 method [25, 26] by using the Gaussian09 suite of programs [27].

\subsection{Molecular docking studies}

In all the molecular docking studies (that constitute the second phase of this study), 4OR0 protein data bank code was selected as the crystal structure of BSA. AutoDock4.2 [28, 29] and Auto Dock Tools (ADT) software were used to calculate the binding energies in the docking studies. The Lamarckian genetic algorithm was used, the genetic algorithm (GA) cycle was selected as 150 , and the maximum number of evaluations was 25 million. The selection of the binding site in BSA was determined as the $x, y, z$ coordinates of the carbonyl carbon of the amino acid TRP213 as the center atom of a cube measuring $50 \times 50 \times 50 \AA^{3}$. Each docking run was repeated 10 times for trimer and tetramer complex structures separately. The central metal ions in the trimer and tetramer complex structures, which were determined to be the most stable configuration, were displaced respectively to obtain structures for the calculation of the binding energy in the protein for each metal ion (Fig. 2). For the 8 metal ions (including $\mathrm{Cd}^{2+}$, $\mathrm{Co}^{2+}, \mathrm{Cu}^{+}, \mathrm{Cu}^{2+}, \mathrm{Fe}^{2+}, \mathrm{Mn}^{2+}, \mathrm{Ni}^{2+}$ and $\mathrm{Zn}^{2+}$ ) the same approach was applied respectively. The selection of ions was done according to experimental data supplied by the work of Karahan et al. [30], with the only exception of $\mathrm{Cu}^{+}$ion being included for its importance in metal catalysis.

\section{Results}

The results of semi-empirical PM6 calculations for the determination of the stable conformer of the complex formed between the metal ion and the PAA are listed in Table I. The trigonal planar conformation is the most stable for the trimer structure of the BSA-metal ion complex, the second stable conformation is T-shaped with a small energy difference $\left(0.11 \mathrm{kcal} \mathrm{mol}^{-1}\right)$. In other conformal forms having different number of cores, trigonal bipyramid conformation has been found the most stable. In tetramer configuration, tetrahedral conformation comes with a very small relative energy $\left(1.23 \mathrm{kcal} \mathrm{mol}^{-1}\right)$ close to the trigonal bipyramid.

According to our results, trigonal structures in both trimer and tetramer configurations are the most stable conformations (Fig. 2a,b).

Relative conformational stability $\left(\mathrm{kcal} \mathrm{mol}^{-1}\right)$ TABLE I

\begin{tabular}{l|c|l|c}
\hline $\begin{array}{c}\text { Conformation } \\
\text { species }\end{array}$ & $\begin{array}{c}\text { Relative } \\
\text { energy }\end{array}$ & \multicolumn{1}{c|}{$\begin{array}{c}\text { Conformation } \\
\text { species }\end{array}$} & $\begin{array}{c}\text { Relative } \\
\text { energy }\end{array}$ \\
\hline \multicolumn{2}{c}{ Dimer } & \multicolumn{2}{c}{ Trimer } \\
\hline linear & 0.00000 & trigonal planar & 0.00000 \\
Tetramer & T-shaped & 0.115177 \\
trigonal planar & 0.00000 & tetrahedral & 8.565730 \\
tetrahedral & 1.23599 & seesaw & 8.799737 \\
octahedral & 1.25526 & octahedral & 9.418905 \\
square planar & 1.38901 & trigonal bipyramid & 9.458939 \\
seesaw & 1.80375 & square planar & 20.44486
\end{tabular}
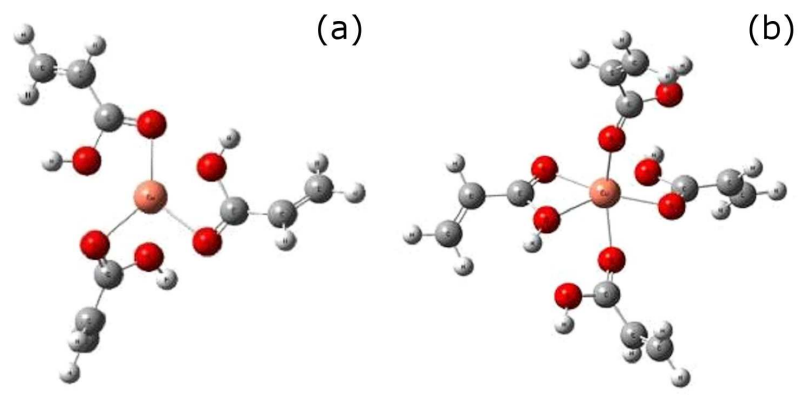

(b)

Fig. 2. The most stable configurations of metal complexes: (a) trimer-trigonal bipyramid, (b) tetramertrigonal bipiramid (the metal ion is $\mathrm{Cu}^{+}$in the figures).

We performed docking studies between the complex that is identified as the stable conformation of the PAA$\mathrm{Cu}^{+}$metal ion (for trimer and tetramer forms, respectively) and BSA. The result of the docking study involving the binding energy and conformation of surrounding amino acids in the active site, we have found that tetramer $\mathrm{PAA}-\mathrm{Cu}^{+}$metal ion complex structure is more compatible with the binding region of BSA (binding energies: $-8.15 \mathrm{kcal} \mathrm{mol}^{-1}$ for the tetramer and $6.15 \mathrm{kcal} \mathrm{mol}^{-1}$ for the trimer structures). Relying on this observed characteristic in the binding region, all experiments were carried out on tetrameric trigonal bipyra- 
midal structures of PAA-metal ion complexes. The binding energy results obtained for the BSA-metal ion-PAA complexes are listed in Table II below.

The results show that the binding energy of the BSAmetal ion-PAA complexes is the most stable complex with the $\mathrm{Cu}^{+}$ion.

Binding energy results $\left(\mathrm{kcal} \mathrm{mol}^{-1}\right)$

TABLE II

\begin{tabular}{c|c|c|c}
\hline \hline \multicolumn{1}{c|}{ Complex } & $\begin{array}{c}\text { Binding } \\
\text { energy }\end{array}$ & Complex & $\begin{array}{c}\text { Binding } \\
\text { energy }\end{array}$ \\
\hline BSA-Cu $\mathrm{Cu}^{+}$-PAA & -8.15 & $\mathrm{BSA}-\mathrm{Co}^{2+}-\mathrm{PAA}$ & -6.24 \\
$\mathrm{BSA}-\mathrm{Cu}^{2+}$-PAA & -7.40 & $\mathrm{BSA}-\mathrm{Cd}^{2+}-\mathrm{PAA}$ & -6.24 \\
$\mathrm{BSA}-\mathrm{Mn}^{2+}$-PAA & -6.34 & $\mathrm{BSA}-\mathrm{Fe}^{2+}$-PAA & -6.12 \\
$\mathrm{BSA}-\mathrm{Zn}^{2+}$-PAA & -6.27 & $\mathrm{BSA}-\mathrm{Ni}^{2+}$-PAA & -6.06
\end{tabular}

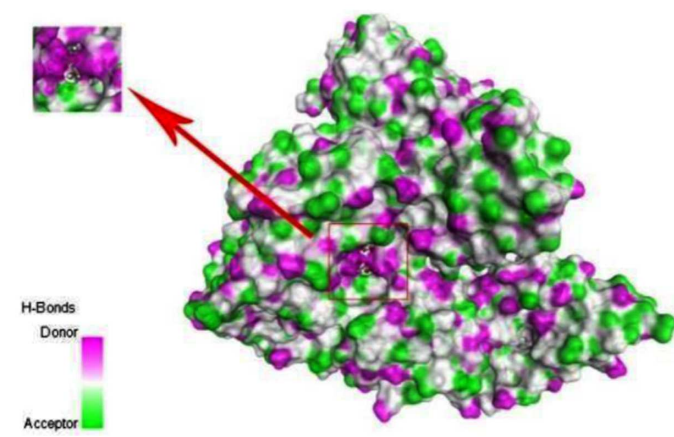

(a)

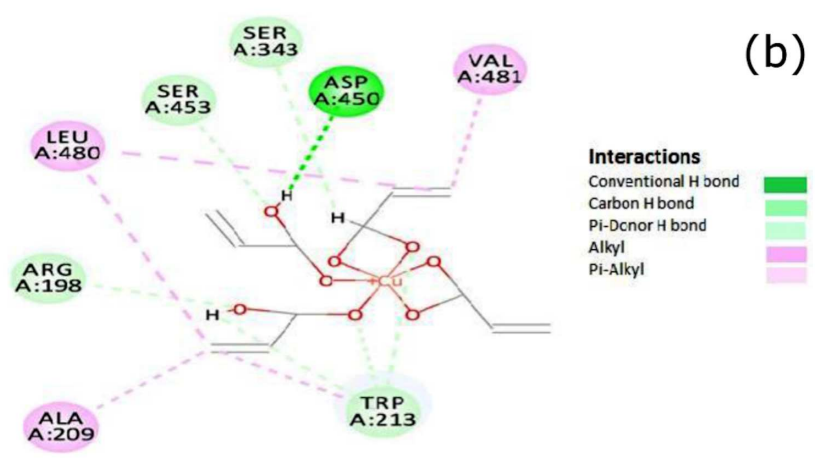

Fig. 3. Interactions with the surrounding amino acids of the $\mathrm{BSA}-\mathrm{Cu}^{+}-\mathrm{PAA}$ complex which gave the best binding energy in the obtained the docking studies (other amino acids are not given for clarity).

Figure $3 \mathrm{~b}$ shows that the $\mathrm{BSA}-\mathrm{Cu}^{+}-\mathrm{PAA}$ complex interacts with a total of 8 amino acids in the binding region. There is a strong interaction especially with ASP450 (H-linked) and SER453, slightly weaker interaction with ARG198, ALA209, TRP213, SER343 LEU 480 and VAL481 residues. Figure $4 \mathrm{a}$ and b shows a strong interaction between amino acid ASP450 and $\mathrm{BSA}-\mathrm{Cu}^{+}$ PAA complex on both sides $(2.02 \AA$ and $2.83 \AA$ interaction distance) as well as a one sided interaction between SER453 and BSA-Cu ${ }^{+}$-PAA complex $(2.53 \AA$ interaction distance). More distant interactions detected in the other complex structures are being studied on.

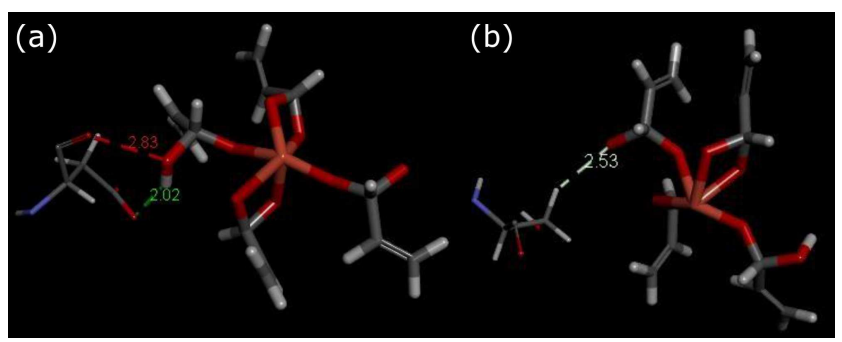

Fig. 4. $\mathrm{Cu}^{+}-\mathrm{PAA}$ interaction with surrounding residues: (a) interaction with ASP450 amino acid, (b) the interaction with SER453 amino acid is shown (Discovery Studio 4.1 Visualizer).

\section{Conclusion}

The $\mathrm{Cu}^{+}$ion has created the most stable complex structure between the transition metal ions, polyacrylic acid and bovine serum albumin. Understanding the importance of the $\mathrm{Cu}^{+}$metal ion, which has not been experimentally studied, has provided valuable data for the selection of transition metals for following experimental work. The results from our docking study are consistent with the experimental data. The obtained results show the importance of determining the coordination number and conformation of the complex formed between the metal ion and PAA and at the same time semi-empirical PM6 method is the right choice. On the other hand, it is thought that docking operation for the studies which is similar to BSA metal ions-PAA complex structure will contribute to the determination of stable complex structures and stability orders.

\section{References}

[1] W. Bal, J. Christodoulou, P.J. Sadler, A. Tucker, J. Inorg. Biochem. 70, 33 (1998).

[2] M. Gharagozlou, D.M. Boghaei, Spectrochim. Acta A Mol. Biomol. Spect. 71, 1617 (2008).

[3] P. Krishnamoorthy, P. Sathyadevi, A.H. Cowley, R.R. Butorac, N. Dharmaraj, Eur. J. Med. Chem. 46, 3376 (2011).

[4] A.K. Bordbar, R. Hosseinzadeh, M.H. Norozi, J. Therm. Anal. Calorim. 87, 453 (2007).

[5] S.S.Y. Seung Kyu Lee, Bull. Kor. Chem. Soc. 29, 234 (2008).

[6] Sock-Sung Yun, Yunghee Oh, Me-A Kang, Young-Inn Kim Bull. Kor. Chem. Soc. 27, 309 (2006).

[7] E. Meggers, Chem. Commun. 9, 1001 (2009).

[8] P. Sathyadevi, P. Krishnamoorthy, R.R. Butorac, A.H. Cowley, N.S.P. Bhuvanesh, N. Dharmaraj, Dalton Trans. 40, 9690 (2011).

[9] W.J. Jusko, M. Gretsch, Drug Metabolism Rev. 5, 43 (1976).

[10] M. Firouzeh, Y. Izadmanesh, E. Aghaee, J. Ghasemi, Bioorg. Chem. 68, 124 (2016).

[11] M.C. Meyer, D.E. Guttman, J. Pharmaceut. Sci. 57, 895 (1968). 
[12] A. Papadopoulou, R.J. Green, R.A. Frazier RA, J. Agric. Food Chem. 53, 158 (2005).

[13] U. Kragh-Hansen, Pharmacol. Rev. 33, 17 (1981).

[14] G. Sudlow, D.J. Birkett, D.N. Wade, Clin. Exp. Pharmacol. Physiol. 2, 129 (1975).

[15] B. Sekula, A. Ciesielska, P. Rytczak, M. Koziołkiewicz, A. Bujacz, Biosci. Rep. $\mathbf{3 6}$, 338 (2016).

[16] D.C. Carter, J.X. Ho, Adv. Protein Chem. 45, 153 (1994).

[17] C. Xin Zhang, S.J. Lippard, Curr. Opin. Chem. Biol. 7, 481 (2003).

[18] R. Bakhtiar, EI. Ochiai, Gen. Pharmacol.. 32, 525 (1999).

[19] Z. Guo, P.J. Sadler, Angew. Chem. Int. Ed. 38, 1512 (1999).

[20] H. Liu, X. Shi, M. Xu, Z. Li, J. Huang, D. Bai, Eur. J. Med. Chem. 46, 1638 (2011).

[21] P. Sathyadevi, P. Krishnamoorthy, E. Jayanthi, R.R. Butorac, A.H. Cowley, N. Dharmaraj, Inorg. Chim. Acta 384, 83 (2012).

[22] F. Samari, B. Hemmateenejad, M. Shamsipur, M. Rashidi, H. Samouei, Inorg. Chem. 51, 3454 (2012).

[23] J. Kong, C.A. White, A.I. Krylov, C.D. Sherrill, R.D. Adamson, T.R. Furlani, M.S. Lee, A.M. Lee, S.R. Gwaltney, T.R. Adams, C. Ochsenfeld, A.T.B. Gilbert, G.S. Kedziora, V.A. Rassolov, D.R. Maurice, N. Nair, Y. Shao, N.A. Besley, P.E. Maslen, J.P. Dombroski, H. Daschel, W. Zhang, P.P. Korambath, J. Baker, E.F.C. Byrd, T. Van Voorhis, M. Oumi, S. Hirata, C.-P. Hsu, N. Ishikawa, J. Florian, A. Warshel, B.G. Johnson, P.M.W. Gill, M. HeadGordon, J.A. Pople, J. Comput. Chem. 21, 1532 (2000).
[24] R. Dennington, T. Keith, J. Millam, Gauss View, Version 5, Semichem Inc., Shawnee Mission, KS 2009.

[25] J.J.P. Stewart, J. Mol. Model. 14, 499 (2008).

[26] J.J.P. Stewart, J. Mol. Model. 15, 765 (2009).

[27] M.J. Frisch, G.W. Trucks, H.B. Schlegel, G.E. Suzerain, M.A. Robb, J.R. Cheeseman Jr., J.A. Montgomery, T. Vreven, K.N. Kudin, J.C. Burant, J.M. Millam, S.S. Iyengar, J. Tomasi, V. Barone, B. Mennucci, M. Cossi, G. Scalmani, N. Rega, G.A. Petersson, H. Nakatsuji, M. Hada, M. Ehara, K. Toyota, R. Fukuda, J. Hasegawa, M. Ishida, T. Nakajima, Y. Honda, O. Kitao, H. Nakai, M. Klene, X. Li, J.E. Knox, H.P. Hratchian, J.B. Cross, V. Bakken, C. Adamo, J. Jaramillo, R. Gomperts, R.E. Stratmann, O. Yazyev, A.J. Austin, R. Cammi, C. Pomelli, J.W. Ochterski, P.Y. Ayala, K. Morokuma, G.A. Voth, P. Salvador, J.J. Dannenberg, V.G. Zakrzewski, S. Dapprich, A.D. Daniels, M.C. Strain, O. Farkas, D.K. Malick, A.D. Rabuck, K. Raghavachari, J.B. Foresman, J.V. Ortiz, Q. Cui, A.G. Baboul, S. Clifford, J. Cioslowski, B. Stefanov, G. Liu, A. Liashenko, P. Piskorz, I. Komaromi, R.L. Martin, D.J. Fox, T. Keith, M.A. Al-Laham, C.Y. Peng, A. Nanayakkara, M. Challacombe, P.M.W. Gill, B. Johnson, W. Chen, M.W. Wong, C. Gonzalez, J.A. Pople, Gaussian 09 (now Gaussian 16), Gaussian Inc., Wallingford (CT) 2016.

[28] S. Cosconati, S. Forli, A.L. Perryman, R. Harris, D.S. Goodsell, A.J. Olson, Expert Opin. Drug Discov. 5, 597 (2010).

[29] S. Forli, A.J. Olson, J. Med. Chem. 55, 623 (2012).

[30] M. Karahan, Z. Mustafaeva, C. Özeroğlu, Protein J. 29, 336 (2010). 